\title{
The effectiveness of the narrative therapy on the fear of negative/positive evaluation and social phobia symptoms in socially anxious female students
}

\begin{abstract}
Introduction: The purpose of this study was to examine the effectiveness of the narrative therapy on the fear of negative/positive evaluation, and social phobia symptoms among the female students in Shiraz, Iran.

Material and methods: Research method was quasi-experimental with pre-test and post-test with experimental and control groups. The sample included 26 subjects, who were referred to psychological centers and were selected by purposive sampling method. The research tools included fear of negative evaluation scale (FNE), fear of positive evaluation scale (FPE), and social phobia symptoms questionnaire. The narration therapy program was performed for the experimental group in eight sessions. In order to analyze data, the covariance analysis was performed using SPSS-22 software. Findings of the study showed a significant difference between the treated and untreated groups for the variables of fear, avoidance, and physiological distress.

Results: The results of univariate analysis for the fear of positive evaluation variable showed a significant difference between treated and untreated groups $(F=7.1, d f=1, P=0.015)$. However, for the fear of negative evaluation variable, the difference was not significant ( $F=0.58, d f=1, P=0.45$ ).

Conclusions: According to these findings, we conclude that narrative therapy is a suitable method in reducing fear of positive evaluation and the treatment of social anxiety.
\end{abstract}

Psychiatry 2020; 17, 4: 181-185

Key words: fear of positive evaluation, narrative therapy, and social anxiety

\section{Introduction}

Social phobia is a persistent fear of social situations; it is the most common anxiety disorder; it is also a risk factor for depression and substance abuse [1]. People with social anxiety disorder are afraid to be examined or observed by others ; they also avoid the situation in which they think they would feel ashamed by saying or doing something [2], when they have communications with others, physical or emotional symptoms appear including fear, trembling, sweating [3], Hertenberg categorized these symptoms into four groups: motor

Adres do korespondencji:

Dorna Afrasiabi

Department of Psychology

University of Isfahan, Shiraz, Iran

e-mail: dorna_afrasiabi@yahoo.com responses, sensitive symptoms, vascular visceral and secretion symptoms and physical symptoms $[4,5]$.

People with social phobia are afraid to be evaluated negatively [6]. According to different studies, SA is highly prevalent among high school, college, and university students and leads to problems related to educational performance [7]. The main cause of SA among students are; presentation, exam, language, and family provocation. Female gender, poor educational performances, and weak social support have been reported as a risk factor of social anxiety [8].

Fear of evaluation plays an important role in social anxiety [9]. Weeks, Roudebaugh, Heimberg [10] declared that patients with social anxiety fear both negative and positive evaluation. Fredrik and Luebbe [11] conside- 
red FNE and FPE as co-occurring cognitive features of social anxiety. Fear of positive evaluation is the feeling of nervousness about other positive evaluation [10]. As Wallace and Adlen [12] have reported: "this nervousness comes from receiving positive evaluation which worries them about the expectation of others in subsequent interactions in the future". On the contrary, fear of negative evaluation is related to the feeling of fear in which one is evaluated negatively [13]. It consists of worries about others evaluations, distress and expectation of negative evaluations [14], negative evaluation is closely related to social anxiety especially in the social situation in which the anxious person is afraid of being evaluated unfavorably [15].

Hence, people with this disorder show infirmity in education place, work, and social life and ultimately, it causes significant distress and disrupts the quality of life. In fact, the individual has a sense of anxiety and worry within himself and in outside has self-made constraints, constraints that prevent a person from using his abilities [16]. Different methods have been used to treat this problem [17]. Although a number of treatments such as exposure therapy, cognitive behavioral therapy, practical relaxation, stress control training seem to be effective, the most well-researched treatment among them is cognitive-behavioral therapy [18], despite the effectiveness of cognitive-behavioral therapies, some people do not show improvements or they drop out of the treatment [19]. Further studies are needed to improve different approaches for the treatment of social phobia [20]. Based on the fact that narrative therapy has an effect on the decrease of shyness, anxiety and depression [21], the present study examines the effectiveness of narrative therapy on the decrease of fear of evaluations and social phobia symptoms. Narrative therapy is a form of therapy which assist individuals to view their problems differently and it also helps them to rely on their talents to decrease problems that exist in their lives. The main principle behind narrative therapy is understanding people within this postmodern context [21]. To understand narrative therapy it is helpful to understand the term narrative; a narrative is a story which is constructed in social context during the past, present and also the future, the narrative is not limited to the story but the meaning which is ascribed to the story by family or a person is important it is their perception which matters regarding their problems or their successes [22]. Analysing narratives, the therapist tries to reconstruct them so that the newly built narratives are not source of patient suffering, new narratives are more appreciative of person's power and responsibility [23], the key concept in narrative therapy is that the problem is not the person, it aims to separate people from their problems [24]. Narrative therapy aims to help individuals improve their relationship with themselves and others [25]. Because of its different perspective on people and problems, it has become popular in therapy field; its perspectives are different from the other approaches, narrative therapy does not consider problems as essential aspects of people or as a result of dysfunctional relationships but resulting from the impact of problems which affects people's lives, three main techniques of narrative therapy are also important for understanding this approach including externalizing the problem, unique outcomes and using relative questioning [22]. It is, therefore, an approach in which it is easy to take the attitude of a certain freedom of conduct; there have been few types of research indicating the clinical usage of narrative therapy until now, especially those in which the effectiveness of the proposed procedure is assessed. Therefore, the aim of this study is to examine the effectiveness of the narrative therapy on the fear of negative/ /positive evaluation and social phobia symptoms among the female students in Shiraz City, Iran.

\section{Material and methods}

A cross-sectional study was conducted at the University of Shiraz from May to July 2017, Shiraz Iran. Research method was quasi-experimental with pre-test and post-test with experimental and control groups. 26 female undergraduate students with social/performance anxiety that referred to Shiraz counselling centers were chosen by purposive sampling and put into 2 groups randomly. The samples also scored above 17 in response to the Connor Social Anxiety Questionnaire. Narrative therapy was done on the experimental group in 8 sessions, a pre-test was done before the intervention and post-test was done after 8 sessions. The exclusion criterion for individuals was refusal to attend treatment sessions for more than two sessions. All participants were provided written informed consent.

\section{Instruments \\ Social Phobia Inventory (SPIN)}

It is developed by the Psychiatry and Behavioral Sciences Department at Duke University. The 17-item SPIN was used to measure anxiety symptoms (measure fear, avoidance, and physiological distress). Fear (of people in authority, of parties and social events, of being criticized, doing things when people are watching and of being embarrassed), avoidance (of talking to strangers, of going to parties, of being a center of attention, of making speeches), and physical discomfort (sweating, palpitation, shaking and trembling in front of others). Each of the 17 items is rated from scale 0 to 4 [26]. The questionnaire uses a Likert-type scale and the minimum score is 17 and 
the maximum score is 85. According to Abdi [27] study, Cronbach's alpha coefficient was 0.94 for the total score and avoidance behaviors, physical symptoms, and social fears were $0.89,0.91$, and 0.80 respectively.

\section{Brief Fear of Negative Evaluation Scale (BFNE)}

The Brief Fear of Negative Evaluation Scale [28] is a 12item measure which uses a 4-point Likert-scale ranging from 0 (not at all characteristic) to 4 (extremely characteristic). The scale has good ability to distinguish individuals with and without anxiety. The BFNE has shown good internal consistency (a ranging from 0.80 to 0.97) [29]. Rostami et al. [30] reported Cronbach's alpha coefficient 0.92 for the total score.

\section{Fear of Positive Evaluation Scale (FPES)}

The Fear of Positive Evaluation Scale [10] is a 10-item scale used to measure fear of positive evaluation from others, with items structured to incorporate social hierarchy dynamics. The FPES uses a 10-point Likert-type scale, ranging from 0 (not at all true) to 9 (very true), to indicate the extent to which each item pertains to individuals that he or she "does not know very well" (e.g., I generally feel uncomfortable when people give me compliments). This measure has good internal consistency ( $\alpha=0.80)$.

\section{Research method}

Narrative therapy training courses are held in 8 sessions (each session $=90 \mathrm{~min}$ ) with the following topics:

1. Introduction: introduction of group members, setting goals and the urge to explain their narratives.

2. Life story: externalizing problems

3. The important life events: the dominant element in the story

4. Deconstruction: unique outcomes, naming the problem

5. Creativity: challenging the narratives, positive and negative factors, big life challenges.

6. Recreating and retelling the story: the critical point, applying the new elements in narratives, preferences, wishes, important goals and people in life, determining the life frameworks.

7. Unique outcomes: analysis of the new narrative's relation to the individual's life.

8. Re-authoring the life story: predicting the potential problems, the final editing of the new narrative.

\section{Results}

The mean total post-test scores for the entire sample of the social anxiety symptoms in the treatment group was $21.5(S D=6.1)$, and for the categories of fear, avoidance, and physiological distress were $8.1(S D=2.2)$,
$9.6(S D=3.1)$, and $4.2(S D=2.2)$, respectively. The Cronbach's alpha was 0.79 for the total scale and the fear, avoidance, and physiological distress subscales were 0.72 , 0.68 and 0.63 , respectively. Significance level based on Levene's test was lower than 0.05 only for fear subscale. Box's M test was used to check the homogeneity of covariance, and the results showed equal variances (Box's = 17.1, $P=0.201)$. The comparison of the mean pre-test and post-test scores of the social anxiety symptoms scale in both control and treatment groups is illustrated in Figure 1. The results of multivariate analysis of variances showed that there was a significant difference between the two groups on the variables of fear, avoidance, and physiological distress (Table 1). But overall, there was no significant difference in total scores between the two groups ( $F=0.71, d f=1, P=0.14)$. The mean scores of experimental and control groups after treatment showed that the average score for social anxiety in the experimental group was lower than the control group. The mean total post-test scores for the entire sample of the fear of negative and positive evaluation in treatment groups were $34.6(S D=3.8)$, and 21.9 $(S D=9.2)$, respectively. The equality of variances checked by Levene's test and analysis showed that variances were not equal for the fear of positive evaluation (Levene's test $=5.55, \mathrm{df}=2, \mathrm{P}=0.02$ ), but for the fear of negative evaluation variable variances was equal (Levene's test $=$ $0.065, d f=2, P=0.80$ ). The comparison of the mean pre-test and post-test scores of the fear of negative and positive evaluation in both control and treatment groups is illustrated in Figures 2 and 3. The results of univariate analysis of variance showed that there was a significant difference between the two groups in the fear of positive evaluation variable scores $(F=7.1$, $d f=1, P=0.015)$. However, in the fear of negative evaluation variable, the difference was not significant $(F=0.58, d f=1, P=0.45)$.

\section{Discussion}

The purpose of this study was to investigate the effectiveness of narrative therapy on reducing the fear of positive/negative evaluation and social anxiety among female students, and the results suggest that narrative therapy had a significant effect on reducing the subscales of social anxiety symptoms. However, this difference was not significant in the overall scores. The total scores of social phobia were 21.5 for the experimental group and those of the control group, 33.4. This difference between control and experimental groups was not significant. According to Ghavami et al. [21] study, the mean scores of social phobia for the experimental and control groups were 65.73 and 104.40 , respectively, and that difference 


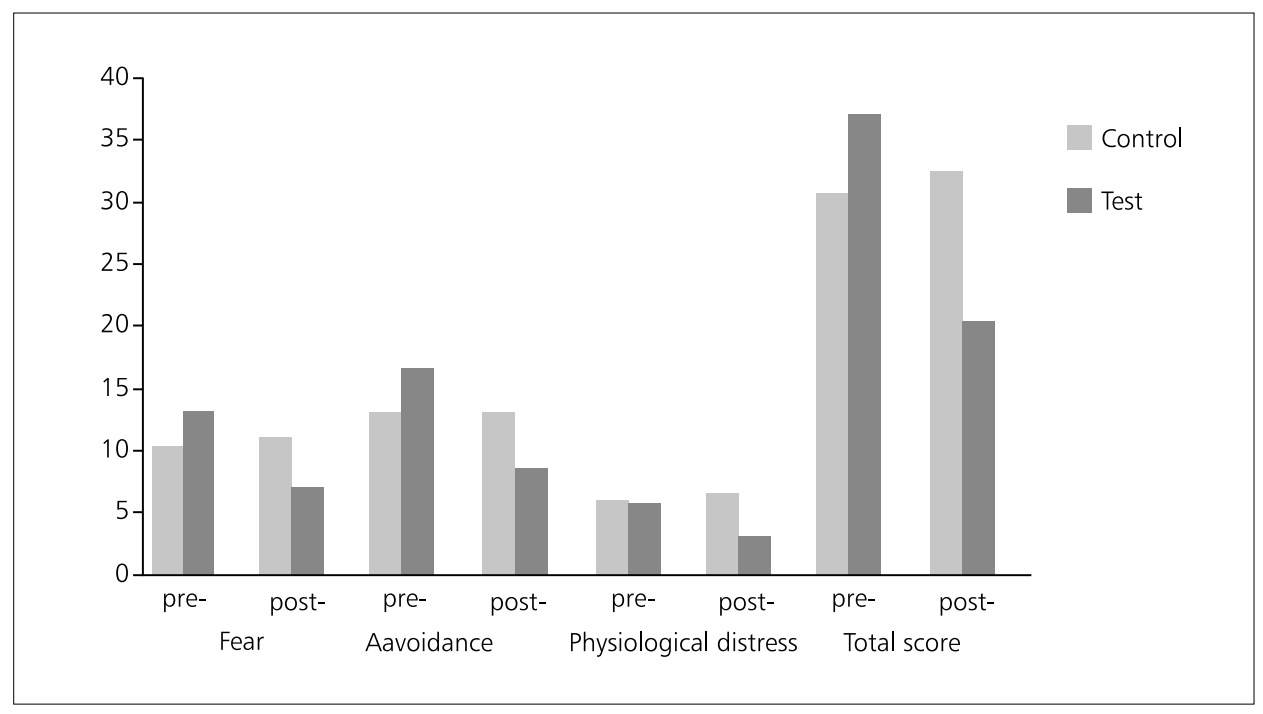

Figure 1. The comparison of the mean pre-test and post-test scores of the Social Anxiety Symptoms Scale

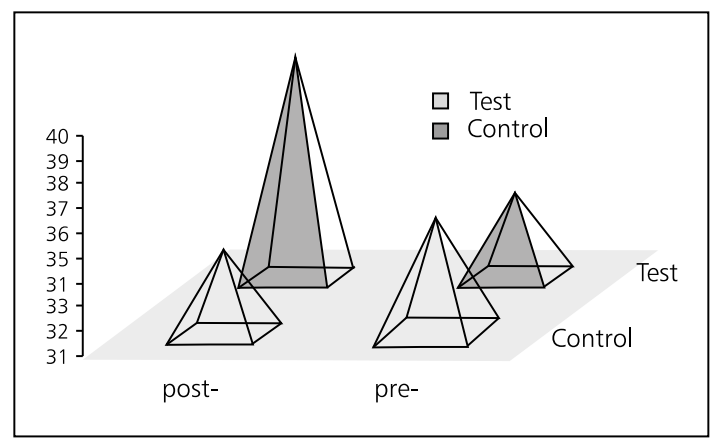

Figure 2. The comparison of the mean pre-test and post-test scores of the fear of negative evaluation

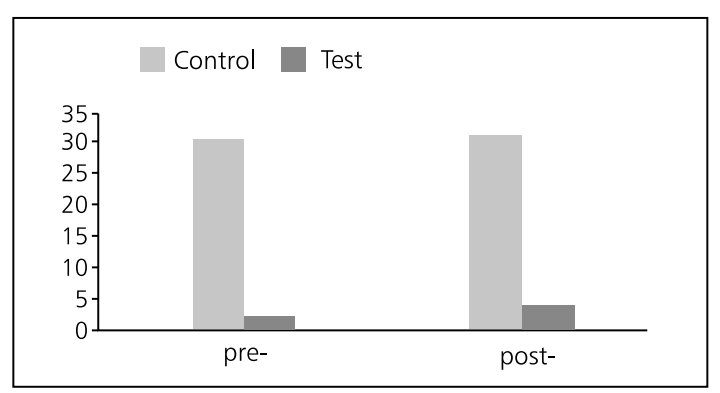

Figure 3. The comparison of the mean pre-test and post-test scores of the fear of positive evaluation was significant in the posttest level: $P<0.01$. These findings were in line with Kamali and Yoosefi Looyeh [20] and Rahmani and Moheb [31] and Ghavami et al. [21], Dadsetan et al. [32]. Narrative therapy had an effective way to reduce anxiety in the experimental group after training has been reported in various studies [32, 33]. The findings of this study also indicate that narrative therapy has a significant effect on reducing fear of positive evaluation. This finding is similar to Fergus et al. [34] study, in that study, the fear of positive evaluation was sensitive to the effects of cognitive-behavioral therapy. Fear of positive evaluation is a strong predictor of state anxiety according to the traditional cognitive conceptualization of social anxiety. Regarding the effectiveness of narrative therapy on reducing anxiety, this study can be repeated in populations and other samples with sufficient sample size are required. Given the scarcity of narrative therapeutic research, the study of other psychiatric disorders are suggested. It is recommended that follow-up courses be included in future research plans to measure the continuity of changes, and also it is suggested that this method be examined individually and the results compared with the present study findings.

Table 1. The comparison of the fear, avoidance, and physiological distress subscales between control/test groups

$\begin{array}{llccc}\text { Variable } & \text { P value } & \text { F value } & \text { Df } & \text { Effect Size } \\ \text { Fear } & 0.011 & 6.90 & 1 & 0.29 \\ \text { Avoidance } & 0.002 & 10.3 & 1 & 0.37 \\ \text { Physiological } & 0.017 & 7.20 & 1 & 0.30 \\ \text { distress } & & & & \end{array}$




\section{Conclusion}

The findings of the present study suggest that social anxiety and fear of positive evaluation scores of the experimental group was changed after narrative therapy. This indicates the impact and importance of narrative therapy in reducing fear of positive evaluation and the treatment of social anxiety.

\section{References:}

1. American Psychiatric Association. (2004). Diagnostic and statistical manual of mental disorders (DSM-IV-TR). Washington, DC: American Psychiatric Association.

2. Stein M, Stein D. Social anxiety disorder. The Lancet. 2008; 371(9618): 1115-1125, doi: 10.1016/s0140-6736(08)60488-2.

3. Cox BJ, Fleet $C$, Stein MB. Self-criticism and social phobia in the US national comorbidity survey. J Affect Disord. 2004; 82(2): 227-234, doi: 10.1016/j.jad.2003.12.012, indexed in Pubmed: 15488251 .

4. Wittchen $\mathrm{HU}$, Fuetsch $\mathrm{M}$, Sonntag $\mathrm{H}$, et al. Disability and quality of life in pure and comorbid social phobia--findings from a controlled study. Eur Psychiatry. 1999; 14(3): 118-131, doi: 10.1016/s09249338(99)80729-9, indexed in Pubmed: 10572336.

5. Ahmadi S, Borghei S, Abbassi Z. Comparison between the effect of education on the basis of attachment narrative therapy and apirituality on marital conflicts. Islam and Psychological Research Journal Quarterly. 2016; 2(4): 99-112.

6. Fairbrother $\mathrm{N}$. The treatment of social phobia -100 years ago. Behaviour Research and Therapy. 2002; 40(11): 1291-1304, doi: 10.1016/s0005-7967(01)00139-5.

7. Murray BS, Lee S. Advances in recognition and treatment of social anxiety disorder: a 10-year retrospective. Psychopharmacol Bull. 2003; 37: 97-107.

8. Dell'Osso L, Abelli M, Pini $\mathrm{S}$, et al. Dimensional assessment of DSM-5 social anxiety symptoms among university students and its relationship with functional impairment. Neuropsychiatr Dis Treat. 2014; 10: 1325-1332, doi: 10.2147/NDT.S59348, indexed in Pubmed: 25075191.

9. Levinson CA, Rodebaugh TL, White EK, et al. Social appearance anxiety, perfectionism, and fear of negative evaluation: distinct or shared risk factors for social anxiety and eating disorders? Appetite. 2013; 67: 125-133, doi: 10.1016/j.appet.2013.04.002, indexed in Pubmed: 23583741.

10. Weeks JW, Heimberg RG, Rodebaugh $T L$, et al. Exploring the relationship between fear of positive evaluation and social anxiety. J Anxiety Disord. 2008; 22(3): 386-400, doi: 10.1016/j. janxdis.2007.04.009, indexed in Pubmed: 17531437.

11. Fredrick JW, Luebbe AM. Fear of positive evaluation and social anxiety: A systematic review of trait-based findings. J Affect Disord. 2020; 265: 157-168, doi: 10.1016/j.jad.2020.01.042, indexed in Pubmed: 32090737.

12. Alden $L$, Wallace $S$. Social phobia and social appraisal in successful and unsuccessful social interactions. Behaviour Research and Therapy. 1995; 33(5): 497-505, doi: 10.1016/0005-7967(94)00088-2.

13. Levinson CA, Rodebaugh TL. Social anxiety and eating disorder comorbidity: the role of negative social evaluation fears. Eat Behav. 2012; 13(1): 27-35, doi: 10.1016/j.eatbeh.2011.11.006, indexed in Pubmed: 22177392.

14. Watson D, Friend R. Measurement of social-evaluative anxiety. J Consult Clin Psychol. 1969; 33(4): 448-457, doi: 10.1037/h0027806, indexed in Pubmed: 5810590.
15. Weeks JW, Heimberg RG, Fresco DM, et al. Empirical validation and psychometric evaluation of the Brief Fear of Negative Evaluation Scale in patients with social anxiety disorder. Psychol Assess. 2005; 17(2): 179-190, doi: 10.1037/1040-3590.17.2.179, indexed in Pubmed: 16029105.

16. Shields M. Social anxiety disorder - beyond shyness. Health Rep 2004; 15 Suppl: 45-61, indexed in Pubmed: 15748044.

17. Hofmann SG. Cognitive factors that maintain social anxiety disorder: a comprehensive model and its treatment implications. Cogn Behav Ther. 2007; 36(4): 193-209, doi: 10.1080/16506070701421313, indexed in Pubmed: 18049945.

18. Rodebaugh TL, Holaway RM, Heimberg RG. The treatment of social anxiety disorder. Clin Psychol Rev. 2004; 24(7): 883-908, doi: 10.1016/j.cpr.2004.07.007, indexed in Pubmed: 15501560

19. Fogler JM, Tompson MC, Steketee G, et al. Influence of expressed emotion and perceived criticism on cognitive-behavioral therapy for social phobia. Behav Res Ther. 2007; 45(2): 235-249, doi: 10.1016/j.brat.2006.03.002, indexed in Pubmed: 16635478.

20. Kamali K, Looyeh MY. Narrative Intervention. Intervention in School and Clinic. 2013; 48(5): 307-312, doi: 10.1177/1053451212472728.

21. Ghavami M, Sadeghi H, Mohammadi E. The effectiveness of narrative therapy on social anxiety and self-esteem of middle school students. J School Psych. 2014(3): 29-42.

22. Kaptain DC. Narrative group therapy with outpatient adolescents. lowa State University 2004.

23. Polkinghorne DE. Narrative therpy and postmodernism. In: Angus LE, Mcleod J. ed. The handbook of Narrative and paychotherapy. Sage publications India Pvt 2004.

24. Etchison M, Kleist D. Review of Narrative Therapy: Research and Utility. The Family Journal. 2016; 8(1): 61-66, doi: 10.1177/1066480700081009.

25. Monk C, Winslade J, Crocket K, Epston D. Narrative therapy in practice, the archaeology of hope. Jossey Bass, San Francisco 1997.

26. Connor KM, Davidson JR, Churchill LE, et al. Psychometric properties of the Social Phobia Inventory (SPIN). New self-rating scale. $\mathrm{Br}$ Psychiatry. 2000; 176: 379-386, doi: 10.1192/bjp.176.4.379, indexed in Pubmed: 10827888.

27. Abdi R. Interpretation bias in patients with social phobia. Dissertation M.S. Tehran Psychiatric Institute. Tehran University of medical sciences, Tehran 2004.

28. Leary M. A Brief Version of the Fear of Negative Evaluation Scale. Personality and Social Psychology Bulletin. 2016; 9(3): 371-375, doi: 10.1177/0146167283093007.

29. Carleton RN, Collimore KC, Asmundson GJG. Social anxiety and fear of negative evaluation: construct validity of the BFNE-II. J Anxiety Disord. 2007; 21(1): 131-141, doi: 10.1016/j.janxdis.2006.03.010, indexed in Pubmed: 16675196.

30. Rostami M, Veisi N, Jafarian Dehkordi F, et al. Social anxiety in students with learning disability: Benefits of acceptance and commitment therapy. Practice in Clinical Psychology. 2014; 2(4): 277-284.

31. Rahmani P, Moheb N. The effectiveness of clay therapy and narrative therapy on anxiety of pre-school children: a comparative study. Procedia - Social and Behavioral Sciences. 2010; 5: 23-27, doi: 10.1016/j.sbspro.2010.07.044.

32. Dadsetan Pari R, Anari A, Saleh Sedghpour B. Social anxiety disorder and drama therapist. Journal of Iranian Psychologists. 2008; 4(14): 115-123.

33. Abolghasemi, Sh. Comparison of four methods Cognitive behavioral, pharmacologic combination and placebo in the treatment of generalized anxiety, PhD thesis. Azad University of Tehran. Science and Research, 2003.

34. Fergus TA, Valentiner DP, McGrath PB, et al. The Fear of Positive Evaluation Scale: psychometric properties in a clinical sample. J Anxiety Disord. 2009; 23(8): 1177-1183, doi: 10.1016/j. janxdis.2009.07.024, indexed in Pubmed: 19700259. 